\title{
A Conceptual Framework for Reducing Changeover Time in Batch Production Facilities
}

\author{
Zainab Eldardiry \\ Al-Arabi Group, \\ Menoufia, Egypt
}

\author{
Mohamed A. El-Dardiry \\ Production Engineering Department, \\ Faculty of Engineering, Alexandria \\ University, Egypt
}

\author{
Omayma A. Nada \\ Production Engineering and \\ Mechanical Design Department, \\ Faculty of Engineering, Menoufia \\ University, Egypt
}

\begin{abstract}
Changeover time is typically one of the most critical aspects that significantly affect the overall effectiveness of manufacturing systems. Basically, changeover time has been identified as a major source for efficiency declines in production facilities as it drastically consumes time as well as other resources with no added value. Particularly, in small to medium sized manufacturing systems that rely on batch production in achieving the product variety that can cope with customer requirements, changeover time reduction is a key enabler for achieving the organization strategic objectives. This paper provides a review for the methodologies commonly employed for quick changeover. Besides, it highlights the case studies in literature that successfully employed such methodologies in changeover time reduction. Furthermore, a conceptual framework that provides a systematic and straightforward guide for identifying and improving changeover activities has been presented in this paper. The proposed framework is mainly based on the DMAIC (Define-Measure-Analyze-ImproveControl) and DMADV (Define-Measure-Analyze-Design-Verify) six sigma methodologies. The framework adopted the DMAIC/DMADV as an integrated approach that can be customized to provide the essential roadmap for reducing changeover time.
\end{abstract}

Keywords-DMAIC Methodology; DMADV Methodology; Changeover Time; Quick Changeover; Single Minute Exchange of Die (SMED)

\section{INTRODUCTION}

Manufacturing enterprises currently are challenged by high diversity in customer requirements as well as intricacy of market and competitiveness. Consequently, several manufacturing organizations opted to produce and dispatch products in relatively small batch in order to cope with those challenges [1]. In small to medium size enterprises targeting medium to high variety in small batches, the main objective is to meet customer demand, shorten lead times and reduce inventories. In such environment, there are different types of products per day associated with large variations in material and processes so that it is difficult to achieve uniform production and processing methods. To ensure the timely production for satisfying customer requirements as well as avoiding excessive inventories, such production mode necessitates frequent changeovers between products [2]. Besides, manufacturing organizations started employing production leveling (heijunka) to order achieve smooth and stable utilization of resources [3, 4]. Production leveling entails defining the sequence of manufacturing different products in a mixed model production to balance production minimize differences in the workstation loads. Definitely, production leveling can help in smoothing production peaks and avoiding work overloads as well as enhancing efficiency [5]. Meanwhile, the implementation of production leveling is associated with frequent changeovers. Therefore, quick changeover is considered as prerequisite for responsive production systems [6].

Consequently, quick changeover initiatives are gaining more focus in different industrial applications. Several academic researchers and consultants have introduced many contributions in this field. Particularly, Shingo in 1985 [7], have proposed an approach that is mainly targeted organizational improvement. This is widely known as Shingo's SMED that stands for Single Minute Exchange of Die. The SMED methodology basically targets to quick change of tools in a single minute digit. That is the elapsed time in setups should be reduced to less than 10 minutes [8]. Despite the SMED concept was originally established for improving machine tool changeovers, particularly in exchanging dies in press operations, its principles are applicable for any type of processes [9]. Mainly, the SMED relies on converting the setup activities that necessitates stopping the production unit (internal) into activities that can be done externally while the production unit is functioning. The procedure primarily includes five steps. These include observation and recording of setup tasks, then classifying internal and external ones. Further, converting as much as possible the internal ones to be done externally. This should be followed by streamlining of all tasks, the documentation of setup procedures. Typically, the changeover time can be measured as the time elapsed between the production of the last good part (at the maximum speed) and the production of the first good part (at maximum speed) [7, 10].

Generally, SMED implementation has the advantage of expanding manufacturing capacity as well as enhancing the equipment flexibility. As a result, that makes working with smaller batch sizes more feasible and improves the utilization of the production facility [11]. However, failing the SMED initiatives in some organizations has been highlighted in [1113]. This failure has been basically attributed to only emphasizing on transferring changeover internal tasks to external ones, while ignoring the importance of streamlining internal and external activities by design improvements. It has been argued that the SMED methodology mainly concerned with changing the way the people work rather than physically modifying manufacturing equipment $[12,13]$. Further, it has been observed that improvements in changeover are difficult to be sustained in some cases. Besides, it has been reported that changeover reduction initiatives are usually attempted in a 
relatively ill-structured, ad hoc style that lacks top management commitment needed for major modifications rather than relying only on organizational improvements that lack sustainability on the long term [14]. It has been also reported that the changeover time reduction based on Shingo's SMED mostly focuses on scenarios including simple one machine and one operator rather than multi-stage production lines or cells [15].

Therefore, this paper proposed a framework that provides a simple and straightforward framework for changeover time reduction. The framework does not only provide a structured methodology for changeover time reduction, but it also integrated options of making major design modifications. Besides, it entails a control phase such that the obtained results can be easily sustained. The presented framework basically integrates and customizes the DMAIC (DefineMeasure-Analyze-Improve-Control) and DMADV (DefineMeasure-Analyze-Design-Verify) six sigma methodologies to provide the essential roadmap for reducing changeover time.

\section{LITERATURE REVIEW}

Several review articles have highlighted the research considered the quick changeover practices. For instance, a review of 130 articles concerned with SMED from 1995 to 2018 has been conducted and introduced in [16]. Another review article also on SMED addressed 70 publications from 2007 to 2018 [17]. Further, earlier reviews have been also presented in [18, 19]. These articles have classified the literature on SMED based on different categories such as fields of implementation, research methods, tools employed, and countries as well. The successful implementation of quick changeover will be highlighted and different case studies in the literature will be reviewed in this section.

For instance, in a printing facility, it has been reported that the changeover time has been reduced through converting $45 \%$ of the internal setup activities into external ones. Besides, improvements in internal setup times have achieved using the 5S methodology which results in further significant improvements in changeover time and production capacity as well [20]. In an Aluminum profile company that has an extrusion line working in batches with frequent changes of dies, it has been demonstrated that implementing SMED can result in savings of about $5 \%$ to $15 \%$ in running cost with simultaneous increase in production capacity [21]. Likewise, the use of SMED approach in one of the SIM card manufacturing companies has enhanced the company's capability in efficiently manufacturing wide range of products. The SMED implementation has resulted in reducing the nonvalue-added labor hours spent on setup activities of the module implanting machine. A reported time reduction of about $87.5 \%$. has been achieved accompanied with an overall equipment effectiveness (OEE) $4.7 \%$ improvements [22]. In the surface coating department of a wood manufacturing Company producing fiberboards, implementing the SMED has achieved a $50 \%$ decrease in changeover time. These improvements are attributed to introducing some addition tools and cleaning of workplace in addition to visual storage standards and display along with minor design changes were introduced to improve the changing the instrumentation accompanied with training sessions for operators [23]. In one of the facilities producing Styrofoam products using injection presses, significant time reduction has been realized at low investment cost using SMED technique [9]. Meanwhile, the SMED implementation at a metal barrel manufacturing cite has also improved the changeover loss [24]. In the pharmaceutical industry, economic benefits from the SMED implementation have been reported in changeovers between products on a certain packaging machine [25]. In one the metallurgical factories, long setup times along with complains of works from shoulder pains and tendinitis during performing manual tasks have been identified as the major productivity problems. Using the SMED principles and enhancing the ergonomic circumstances have resulted in $46 \%$ reduction in setup times and decreased the risk of workers' injuries as well [26]. In gears production, the SMED has improved the unproductive time of honing shafts which resulted in tangible capacity improvements [27].

In the literature the SMED methodology has been widely integrated with other improvement methodologies. Typically, it has been employed along with other lean tools such as $5 \mathrm{~S}$, visual management, Kanban, Total Productive Maintenance (TPM), and Kaizen [20, 25, 28-33]. For instance, to improve the changeover process in a five-axis CNC machine operation, the conventional SMED method has been integrated with other process improvement tools such as the cause-and-effect analysis, five whys analysis [32]. Similarly, to increase flexibility and productivity of a seat-cable assembly line at an automotive company, $5 \mathrm{~S}$, operators training, and visual aids have incorporated with SMED. This has resulted in $58.3 \%$ reduction in setup times [33]. Besides, other tools such as Taguchi experimental design has been also employed along with SMED in injection molding production [31]. Furthermore, the value stream mapping (VSM) as one of the lean tools has been effectively used with the SMED and promising results have been achieved. VSM and SMED enabled a reduction in the nonvalue added activities related to changeover time by $34 \%$ and increased the production capacity of a particular line $11 \%$ in a food processing industry [34]. Additionally, some studies considered the enhancement of changeover capabilities through considering the quick changeover during the equipment design stage. The awareness of the importance of having short changeover along with some design guidelines can support designing equipment for quick changeover $[13,35,36]$.

\section{THE PROPOSED CONCEPTUAL FRAMEWORK}

In this paper, a conceptual framework for improving changeover process is presented as shown Fig. 1. The suggested framework basically adopted the DMAIC (DefineMeasure-Analyze-Improve-Control) six sigma methodology and customized it for the sake of reducing changeover time. The first phase in this framework is the Define phase which is mainly concerned with monitoring the manufacturing process to identify the frequency of changeover as well as the changeover activities. The framework can be employed either for simple process involving one machine or a whole production line with several processes. It is important at this phase to identify all the changeover activities along the production processes. 


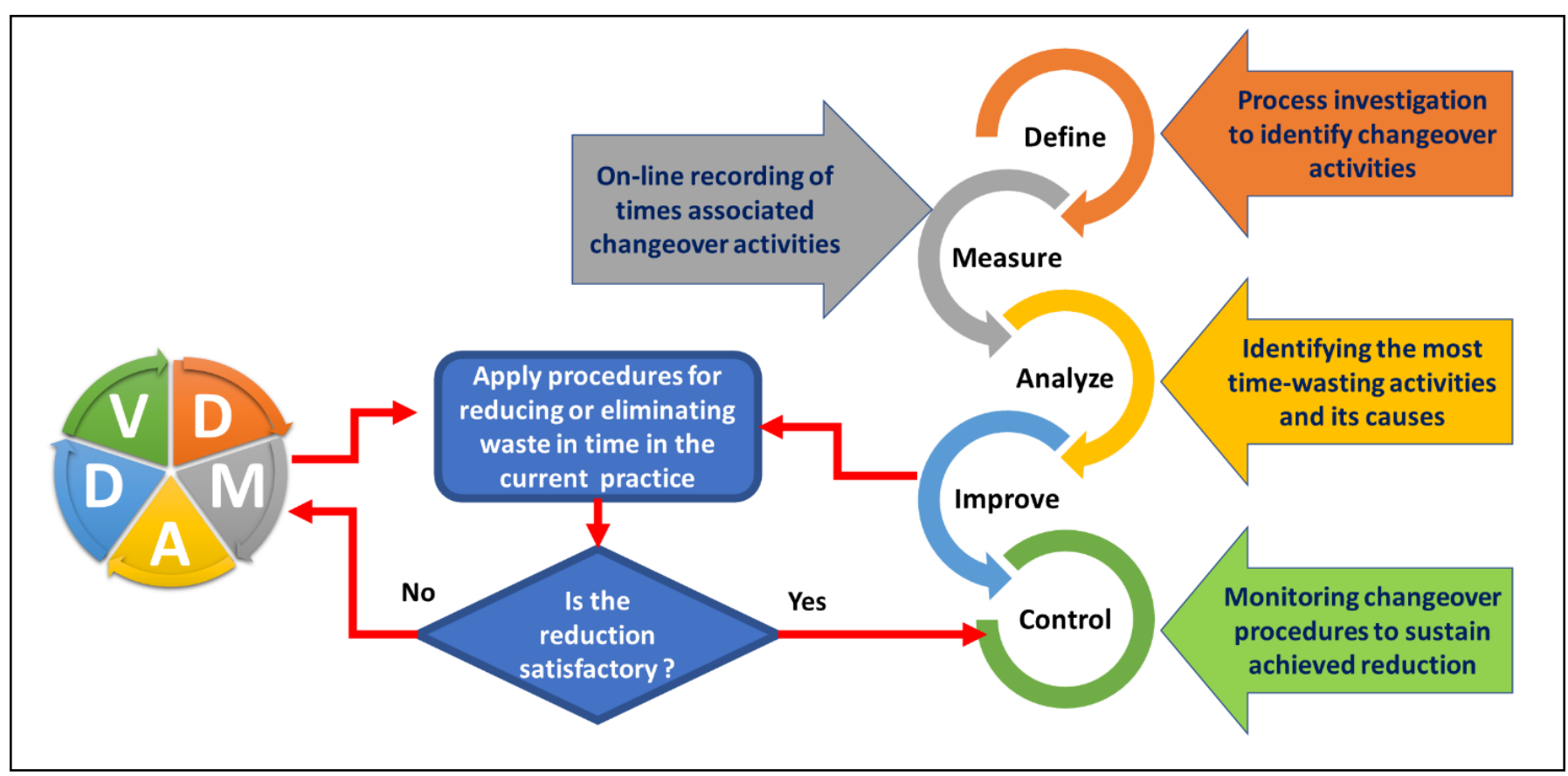

Fig. 1. The proposed conceptual framework for changeover time reduction

The second phase is the Measure phase, in which all the changeover activities should be monitored and video recorded to assess the current practices and their associated times. In this phase it is critical to employ several tools such as Value Stream Mapping. In such applications, a current state value stream map should be constructed to model the steps included in the changeover process itself not the manufacturing processes. This can significantly help in identifying the nonvalue-added activities during changeover. Besides, check sheets can be also used for collecting and organizing data.

The third phase is the Analyze phase which is concerned with using tools such Pareto analysis to identify the most time-consuming activities. This can help in focusing the improvement efforts on the most critical nonvalue added activities in the changeover process. Besides, in case of dealing with a manufacturing line with changeovers in different process, the Pareto analysis can prioritize these changeover processes according to the time losses associated with them. In this phase, it is also essential to conduct brain storming sessions with manufacturing team to investigate the process to identify the causes of long changeovers. Tools such as cause and effect diagram as well as 5 why analysis can be implemented in this phase to identify the root causes of times losses in changeover processes.

The fourth phase of this framework is the Improve phase that is concerned with implementing ideas and techniques for reducing changeover time. This phase includes employing the guidelines included in the SMED methodology. This SMED entails transforming as much as internal changeover activities into external ones along with simplification of all activities and elimination of the unnecessary activities. In the improvement phase, other lean tools such as the $5 \mathrm{~S}$ approach can be employed to organize the workplace, which be its turn can significantly affect the work environment. Besides, job aids, visual management, and work standards can be also employed to make the changeover tasks easier to perform. In is critical also to investigate the ergonomics of tasks and work environment to enhance the workers performance. Additionally, all the required operators training should be considered during this phase.

After accomplishing the recommended improvements, the achieved reduction should be assessed in terms of the amount of time saved and the sustainability of the achieved results. If these achieved results are satisfactory, one should proceed to the final step which is the Control phase. This phase is very critical because it has a significant role in sustaining the achieved improvements. This phase involves the changeover process documentation and monitoring to assure that the work instructions are being strictly followed to sustain the achieved reductions in changeover time.

While if the achieved reductions in changeover time are not satisfactory either in terms of the amount of reduction or the sustainability, it is recommended start making design modifications by following the DMADV (Define-MeasureAnalyze-Design-Verify) methodology. It involves five phases that starts with identifying the objectives of design modifications in the Define phase, followed by the Measure phase to identify the key characteristics that affect the changeover activities. Then, in the Analyze phase, different alternatives for design modifications should be generated and assessed to select the most appropriate one. In this phase, different design guidelines as well as the principles of design for changeover can be employed as recommended in $[6,13$, 35]. This should be followed by providing the details of the proposed design modifications, which is known as the Design phase. The last stage is the Verify phase that entails the verification of the proposed design either through simulation or pilot runs on a prototype. After completing the DMADV 
cycle, the modifications are employed and assessed and if the reduction is satisfactory, one should proceed to the control phase of the DMAIC cycle.

\section{CONCLUSION}

Quick changeover has become a prerequisite for coping with high variety in customer requirement while maintaining high utilization of production resources, particularly in batch production systems. The effectiveness of changeover reduction approaches can be mainly assessed based on the changeover time reduction, as well as the sustainability of the achieved results. Despite the effectiveness and sustainability associated making major design changes to reduce changeover time, such approaches are more costly. Therefore, this paper has introduced a framework that integrates both of DMAIC and DMADV six sigma methodologies to achieve the targeted reduction in changeover time. Since the modifications in the already existing changeover practices do not cost as much as the major design modifications or the new designs, the proposed framework starts with the DMAIC methodology to initially target improving the current practice. Meanwhile, to overcome the sustainability issues, the DMAIC phases entails a control phase for sustaining the achieved improvements. In case of unsatisfactory results, major design modifications or new designs can be achieved through following the DMADV phases. Hence, the suggested framework can provide the improvement team with a well-structured straight forward methodology that integrates all the available options for changeover time reduction.

\section{REFERENCES}

[1] A. C. Garavelli, "Performance analysis of a batch production system with limited flexibility," International Journal of Production Economics, vol. 69, pp. 39-48, 2001.

[2] X. F. Chang, "Challenges posed by multi variety and small batch production mode and countermeasures acted by Chinese small and medium enterprises," in Advanced Materials Research, 2013, pp. 794 798.

[3] L. F. De Araujo and A. A. De Queiroz, "A conceptual model for production leveling (heijunka) implementation in batch production systems," in IFIP International Conference on Advances in Production Management Systems, 2009, pp. 81-88.

[4] D. Powell, E. Alfnes, and M. Semini, "The application of lean production control methods within a process-type industry: the case of hydro automotive structures," in IFIP International Conference on Advances in Production Management Systems, 2009, pp. 243-250.

[5] P. Rewers, A. Hamrol, K. Żywicki, M. Bożek, and W. Kulus, "Production leveling as an effective method for production flow control-experience of polish enterprises," Procedia Engineering, vol. 182, pp. 619-626, 2017.

[6] A. Mileham, S. Culley, G. Owen, and R. McIntosh, "Rapid changeover-a pre-requisite for responsive manufacture," 1998.

[7] S. Shingo, A revolution in manufacturing: the SMED system, 1st ed.: Productivity Press, 1985.

[8] K. Arai and K. Sekine, Kaizen for quick changeover: Going beyond SMED: CRC Press, 1992.

[9] B. Ulutas, "An application of SMED Methodology," World academy of science, engineering and technology, vol. 79, p. 101, 2011.

[10] K. Herr, Quick Changeover Concepts Applied: Dramatically Reduce Set-Up Time and Increase Production Flexibility with SMED: Productivity Press, 2013.
[11] P. G. Ferradás and K. Salonitis, "Improving changeover time: a tailored SMED approach for welding cells," Procedia CIRP, vol. 7, pp. 598603, 2013.

[12] R. McIntosh, G. Owen, S. Culley, and T. Mileham, "Changeover improvement: reinterpreting Shingo's "SMED" methodology," IEEE Transactions on Engineering Management, vol. 54, pp. 98-111, 2007.

[13] R. McIntosh, S. Culley, G. Gest, T. Mileham, and G. Owen, "An assessment of the role of design in the improvement of changeover performance," International Journal of Operations \& Production Management, 1996.

[14] G. Gest, S. Culley, R. McIntosh, A. Mileham, and G. Owen, "Review of fast tool change systems," Computer Integrated Manufacturing Systems, vol. 8, pp. 205-210, 1995.

[15] D. Van Goubergen, "Set-up reduction for lean cells and multi-machine situations," in Lean Business Systems and Beyond, ed: Springer, 2008, pp. 295-303.

[16] I. B. da Silva and M. Godinho Filho, "Single-minute exchange of die (SMED): a state-of-the-art literature review," The International Journal of Advanced Manufacturing Technology, vol. 102, pp. 4289-4307, June 012019.

[17] R. Godina, C. Pimentel, F. Silva, and J. C. Matias, "A structural literature review of the Single Minute Exchange of Die: the latest trends," Procedia Manufacturing, vol. 17, pp. 783-790, 2018.

[18] Y. Dave and N. Sohani, "Single minute exchange of dies: Literature review," International Journal of Lean Thinking, vol. 3, pp. 27-37, 2012.

[19] R. R. Joshi and G. Naik, "Reduction in setup time by SMED a literature review," International Journal of Modern Engineering Research (IJMER), vol. 2, pp. 442-444, 2012.

[20] S. Indrawati and M. E. Pratiwi, "The effectiveness of single minute exchange of dies for lean changeover process in printing industry," in MATEC Web of Conferences, 2018, p. 01064.

[21] R. Assaf and T. H. Haddad, "An Application of Single Minute Exchange of Die Approach in an Aluminum Profiles Extrusion Production System: Case Study," 2017.

[22] S. Jain and R. O. Vaishya, "Case study: application of SMED in SIM card manufacturing company," International Journal of Productivity and Quality Management, vol. 32, pp. 109-128, 2021.

[23] J. Trojanowska, K. Żywicki, M. L. R. Varela, and J. Machado, "Improving production flexibility in an industrial company by shortening changeover time: a triple helix collaborative project," in Multiple Helix Ecosystems for Sustainable Competitiveness, ed Springer, 2016, pp. 133-146.

[24] S. Jebaraj Benjamin, U. Murugaiah, and M. Srikamaladevi Marathamuthu, "The use of SMED to eliminate small stops in a manufacturing firm," Journal of Manufacturing Technology Management, vol. 24, pp. 792-807, 2013.

[25] A.-A. Karam, M. Liviu, V. Cristina, and H. Radu, "The contribution of lean manufacturing tools to changeover time decrease in the pharmaceutical industry. A SMED project," Procedia Manufacturing, vol. 22, pp. 886-892, 2018.

[26] M. Brito, A. Ramos, P. Carneiro, and M. Gonçalves, "Combining SMED methodology and ergonomics for reduction of setup in a turning production area," Procedia Manufacturing, vol. 13, pp. 1112-1119, 2017.

[27] D. Sabadka, V. Molnar, and G. Fedorko, "The use of lean manufacturing techniques-SMED analysis to optimization of the production process," Advances in Science and Technology Research Journal, vol. 11, 2017.

[28] M. Faccio, Y. Cohen, M. Bevilacqua, F. Ciarapica, I. De Sanctis, G. Mazzuto, et al., "A Changeover Time Reduction through an integration of lean practices: a case study from pharmaceutical sector," Assembly Automation, vol. 35, pp. 22-34, 2015.

[29] J. C. R. Jie, S. Kamaruddin, and I. A. Azid, "Implementing the Lean six sigma framework in a small medium enterprise (SME) - a case study in a printing company," in Proceedings of the 2014 International Conference on Industrial Engineering and Operations Management Bali, Indonesia, 2014, pp. 387-395.

[30] K. Arai and K. Sekine, Kaizen for quick changeover: Going beyond SMED: CRC Press, 2006 
[31] M. K. Karasu, M. Cakmakci, M. B. Cakiroglu, E. Ayva, and N. Demirel-Ortabas, "Improvement of changeover times via Taguchi empowered SMED/case study on injection molding production," Measurement, vol. 47, pp. 741-748, 2014.

[32] R. Ahmad and M. S. F. Soberi, "Changeover process improvement based on modified SMED method and other process improvement tools application: an improvement project of 5-axis $\mathrm{CNC}$ machine operation in advanced composite manufacturing industry," The International Journal of Advanced Manufacturing Technology, vol. 94, pp. 433-450, 2018.

[33] C. Rosa, F. Silva, L. P. Ferreira, and R. Campilho, "SMED methodology: The reduction of setup times for Steel Wire-Rope assembly lines in the automotive industry," Procedia Manufacturing vol. 13, pp. 1034-1042, 2017.

[34] M. Maalouf and M. Zaduminska, "A case study of VSM and SMED in the food processing industry," Management and Production Engineering Review, vol. 10, pp. 60-68, 2019.

[35] D. Van Goubergen and H. Van Landeghem, "Rules for integrating fast changeover capabilities into new equipment design," Robotics and computer-integrated manufacturing, vol. 18, pp. 205-214, 2002.

[36] M. Cakmakci, "Process improvement: performance analysis of the setup time reduction-SMED in the automobile industry," The International Journal of Advanced Manufacturing Technology, vol. 41, pp. 168-179, March 012009. 